\title{
The impact of childhood asthma on daily life of the family-a qualitative study using recurrent thematic analysis
}

\section{Barbara P. Yawn}

\begin{abstract}
Aims To study the family burden of childhood asthma.

Methods A qualitative study using focus groups of mothers, analyzed by recurrent thematic analysis, 'immersion-crystallisation' techniques.

Results Three main themes emerged; mothers have unmet needs and expectations regarding asthma, the impact of asthma is pervasive on daily life and childhood asthma is an emotional burden for the family.

\section{Conclusions}

Living with asthma is a constant struggle that can but often is not eased by the health care system.
\end{abstract}

\section{Introduction}

Asthma is the most common chronic childhood disease affecting 10 to $20 \%$ of children sometime before their 18th birthday. ${ }^{1-7}$ Its impact on children's quality of life has been described extensively. ${ }^{1,4,8-10}$ Yet, asthma affects not only the child but also parents, siblings and extended family members. ${ }^{11-16}$

The impact of asthma on families and parents has been studied using primarily well-validated survey instruments. ${ }^{11-20}$ While these data are easy to summarise and compare, the rigid format limits the scope of available responses.

This study used focus groups to allow parents of children with asthma to share information.

Understanding parents' concerns, needs and perceptions of current asthma care could help ensure that future asthma programmes will be responsive to the needs of the entire family.

\section{Methods}

This is a qualitative study using six focus groups of 47 mothers of children with asthma; two each from Arizona, Nebraska, and New Jersey, USA. Recruitment was performed through newspaper advertisements, posters in local physicians' offices and through local asthma support groups. The focus groups were conducted in English although one Hispanic participant brought an interpreter. The children with asthma ranged in age from 6 to 14 and had known asthma for an average of 3.6 years (range 2 months to 8 years). Most parents rated their child's asthma as moderate persistent with one rated as severe and one rated as intermittent.

A semi-structured interview guide was used to allow for consistency of format and sequencing of questions for each group. (Table 1) No modifications to the discussion guide were made during the study period. All facilitators had previous experience leading group discussions. Each 90-minute session was audiotaped and transcribed verbatim.

\section{Data analysis}

A physician and two nurses, independent from the group facilitators, analysed the transcriptions of the six focus groups. Each person read and re-read all transcripts, and developed a detailed list of participants' comments in the five areas addressed by the interview questions. Reviewers compared and cross-referenced every identified response to ensure that all parents' issues, concerns and ideas were included. Themes and domains were identified. The reviewers met several times over the span of eight months to discuss and reassess the overall themes.

This process, known as immersion/crystallization, ${ }^{21}$ conceptualises thematic analysis as an ongoing spiral, first by individual researchers and then reviewed and refined by the team of researchers.

\section{Results}

Three key themes were identified from the focus group discussions (Table 2). Each will be discussed separately.

\section{Table 1. Focus group discussion questions}

The questions were developed to allow participants to provide a broad range of information regarding health beliefs, current health care, their daily life and hopes for improvements in asthma care.

1. What beliefs or "truths" do you have regarding asthma and allergies?

2. What is it like to live with a child who has asthma?

3. What do you think of currently available asthma treatments?

4. Do you have any concerns about indoor air quality?

5. If the world could be perfect, what asthma-related changes would you make?

\section{Table 2. Themes from focus groups}

- Parents have many unmet asthma-related expectations.

- The impact of asthma on daily life is pervasive.

- Asthma results in significant emotional burdens for those with asthma and for parents of children with asthma.

Overall, life with asthma was viewed as a constant struggle. 


\section{1) Parents have many unmet asthma-related expectations}

Parents reported that their medical, school, work and social communities failed to attend to many of their concerns and that their needs and expectations often go unmet. For example, parents wanted to know why their child had asthma. While some parents accepted medical explanations they had been given, others had different asthma-related beliefs about the environment and genetics that they wanted acknowledged and addressed. Several parents made their own searches for plausible explanations of the origins of their child's asthma.

Safe, reliable and responsive high-quality medical care was desired by all. Some parents believed they found what they expected and needed. Others were bothered by incomplete, inconsistent messages regarding asthma severity and management from physicians and worried that their child's asthma care was inadequate or inaccurate. Parents wanted physicians to be capable of diagnosing asthma and either caring for their child with asthma or referring them for specialised asthma care. Parents felt they should be able to expect prompt, accessible and affordable emergency care when they believed the child was having an asthma "attack". Being forced to wait long periods in emergency departments or finding that they could not afford to purchase the prescribed asthma medications lead to fear and frustration.

Asthma therapy, especially medication, was expected to be safe, effective and have few side effects. Some parents believed their children would not be alive without the benefit of asthma medication while others were wary of using multiple medications. Steroids caused special concern. Few parents separated oral steroids and inhaled steroids, simply labelling "steroids" as their concern. Side effects of $\beta 2$-agonists, specifically jitteriness, hyperactivity, and hyper-vigilance were also bothersome.

A few parents expected their children's bodies to learn to compensate for asthma and require no medication. In fact they believed medication use resulted in dependency so they refrained from giving asthma medications.

Parents were concerned about the lack of asthma awareness and support among teachers, coaches, babysitters, physicians and employers. Rural parents expressed concerns about air pollution from "dust storms" and agricultural pollution from insecticides and herbicides. Urban residents were more concerned with molds, "sick" school or work buildings and air pollution from industry and vehicles.

Schools were viewed as rigid, inflexible institutions that lack knowledge regarding the issues and care of children with asthma. Parents described fighting for their child's access to necessary medications. Few schools were believed to have adequate on-site nursing staff, especially nurses with training in asthma assessment or management.

Parents expressed a general lack of trust that school personnel could assess the status of their child's asthma, provide adequate care and determine when to seek medical attention.

\section{2)The impact of asthma on daily life is pervasive (Table 3)}

Asthma affects every aspect of family life. Parents reported that they are constantly on their guard concerning the health of the child with asthma. They must be attentive to situations at school, play, work and home. Most described their experience with asthma as exhausting, stressful, anxiety provoking and frightening.

Families reorganised their households in order to prevent asthma exacerbations, focusing on decreasing allergens, asthma triggers and improving indoor air quality. Most parents attempted to clean, vacuum and dust their homes daily in an attempt to decrease asthma triggers. Many expressed exasperation at their inability to have their house and air clean enough to prevent an asthma attack.

Mothers reported they were usually the parent responsible for childcare. The need to be available for support and care of the child's variable asthma exacerbations limited employment opportunities. Homebound jobs provided flexibility, but few provided health insurance benefits.

Many families felt "financially strapped" due to high costs of asthma medications, office and emergency department visits, environmental controls and loss of work time. For several, the cost demands could not be met. For uninsured families the struggle seemed insurmountable, but even for those with insurance and drug benefit plans the co-payments proved a burden. Specialty asthma care often was not covered under insurance programs and therefore, not accessible.

\section{3) Asthma can result in significant emotional burdens (Table 3)}

For those living with asthma, there was significant worry over the unpredictability of an asthma attack, as well as great fear that one might die. Asthma was described as "life threatening", "crippling", "unpredictable" and "scary". Constant worry existed over possible external or internal causes and/or environmental factors that might trigger an attack. Parents could not sleep at night for listening for their child's breath and had trouble trusting the care of their child to others, whether at school, after-school activities, a friend's house or in the care of a babysitter. There was a pervasive anxiety that never allowed "peace of mind".

Mothers feared their child might die, suffer permanent damage or develop addiction to and severe side effects from asthma medication. They expressed guilt about their inadequacy in the face of asthma; their inability to prevent asthma attacks, their trouble staying employed (earning income) due to the demands of childcare, their need for "down time" away from the responsibility of parenting a child with asthma and for having a family history of asthma and "giving asthma" to their child. 
Original research

Asthma was viewed as a stigmatising disease by many parents who found they must curtail their child's activities due to their illness. Parents spoke about their children feeling "different" when they cannot participate in activities due to their asthma or when it is necessary for them to administer asthma medications in public. Parents were often at odds with their own children concerning medication use.

Parents expressed concern about family dynamics. Mothers were uneasy about the amount of time and attention given to the child with asthma and worried how this affected the other siblings. They perceived that family life was shaped around asthma and the child with asthma. Social events were often cancelled at the last minute due to asthma exacerbations, leaving siblings and parents frustrated.

Feelings of being "all alone" and having little control over what happens were expressed by many parents. Communities were described as insensitive and not knowledgeable regarding asthma, asthma care and environmental hazards such as smoking and pollution that aggravated asthma symptoms.

Insurance companies, physicians and schools were perceived as controlling many aspects of asthma care adding to parents' feelings of a lack of control. Insurance companies allowed little flexibility in the choice of physicians, especially specialists, provided only one inhaler per month and limited access to nebulisers. Helpless feelings were exacerbated when physicians prescribed treatment not financially available to the family.

Written action plans, peak flow meters and a good relationship with the child's physician allowed parents and children to feel a greater sense of control and to make informed decisions about their care.

\section{Overall theme: Struggle}

The overarching theme of these focus groups was that life with asthma was a struggle. Parents and children struggled with the illness itself. They struggled with the medical and insurance professionals to obtain needed care and treatment, with schools to assure access to health personnel knowledgeable about asthma, with employers to obtain job flexibility, and with the community to find support for clean air and a safe, smoke-free environment.

Parents struggled for control of the child's asthma that is at times personally restrictive and at the same time struggled to provide freedom for the child. The daily effort was described as tremendous, taking a toll on individuals and families. They labored to achieve balance within the family unit.

\section{Discussion}

Living with asthma demands great effort that affects every member of the family. While physicians and other health providers can and do help, they often add to the struggle.

\section{Table 3. Parents' comments}

1. Unmet needs and expectations.

Health care services

- "Doctors don't know how serious it (asthma) is, they don't take it seriously."

- "I had to read a lot on my own, 'cause the doctors would not tell me 'cause they really didn't know."

- "Some doctors, insist that a child wheeze before they'll call them an asthmatic, and K. doesn't wheeze. She coughs."

- "The only way I'm able to get my child seen right away...I have to call the ambulance!"

Medications-steroids

- "When my son is on steroids...he's like a monster. ...I can't control him."

- "Steroids make you too hyper."

- "...the doctor prescribes it and I won't fill 'em."

- "I try not to use inhalers often because I feel like your body becomes immune."

• "Don't start treatment, then you won't need it."

Schools

- "People in the schools know more about diabetes and epilepsy than asthma."

- "They don't let them carry (inhalers) until they're ten... "

- "And I tell them, go sneak in the bathroom.... it's horrible to be that deceptive, but you have to."

- "there are a lot of times where I'll just keep him home (from school)...I don't have to worry."

\section{Impact on daily life.}

\section{General}

- "It just becomes all consuming."

- "I think you become less carefree."

- "It's difficult because it never seems to be enough."

Employment

- "The only time I can get health insurance is if I work out of the home, and if I work out of the home, I can't be there for him. So, it's a double-edged sword."

- "If I had to work outside the home, it would just be almost impossible."

Financial pressure

- "I can go to my pediatrician, but I can't get to a specialist - they (insurance) won't pay."

- "You can go to the free clinic, but what good does that do when you can't get the medicine?"

- "It was suggested that we get air conditioning. I rent the place. I can't move and I certainly can't afford air conditioning. It's outrageous."

- "We ended up having to move (due to smoking neighbors in apartment next door), but the rent is three times the amount."

\section{Emotional burden}

- "... a burden on not only the person going through it, but the entire family."

- "... the emotional impact on the mother, ... we go through depression."

- "...I mean he's never been away from us overnight because my mother doesn't want to deal with it. There's nobody that wants to deal with it."

- "Asthma (is) costly, not only for money wise, but in your personal life there are so many things that it keeps you from doing."

Stigma

- "Kids don't like to be different. ...they don't want to have to use their inhalers in front of their friends."

- "... little kids turned to me and said, 'How come Billy has to have so much medication? ... he has more peer issues to deal with."

- "... he fights me from taking his medications. He is at the point where he's just burned out."

Lack of control

- "It took me six months of fighting ...to get the nebulizer."

Things that help

- "My son has written instructions...he is breathing 230 instead of 110 on the peak flow meter. So, I know his medication is doing for him what it is supposed to be doing." 
Families living with asthma want their concerns to be acknowledged and questions answered in a clear and consistent manner. In particular, fear and concerns about medication side effects must be addressed by physicians, nurses and pharmacists, not ignored or downplayed.

Physicians and nurses who provide written information and advocate for necessary medical devices (nebulisers or a second inhaler) increase a family's sense of control. Coaches, teachers and school nurses often frustrate attempts to "normalise" the life of children with asthma, but when knowledgeable and responsive to the child's needs enhance the family's sense of well being.

Communities are also important, either increasing the struggle or facilitating the family's and child's ability to adapt and live well with asthma.

These parents expressed concerns that are very similar to those reported from parents in European and African countries. ${ }^{12,15,19,20}$ The messages were little changed from parental concerns of 20 or 25 years ago, ${ }^{14}$ suggesting that the health care community has not done as well translating the asthma care guidelines into supportive and desired actions as we have done developing the guidelines. ${ }^{22}$

The six focus groups appeared to provide saturation. The last focus group added little new information to the other five. It appears that few of the participants had children with mild or intermittent asthma and almost none appeared to have enjoyed good control throughout the entire period of their child's asthma care. Parents of children with milder disease or those with better control of symptoms may have fewer or different concerns but apparently were not sufficiently motivated to volunteer for focus group participation. Although we included parents from several racial, ethnic and geographic groups, the sample size does not permit stratification by subgroups.

\section{Summary}

\section{Dr Barbara Yawn}

Director of Research

Correspondence to:

Barbara Yawn,

Director of Research

Olmsted Medical Center

210 Ninth St. SE

Rochester, MN 55904

USA

Tel: +1 (507) 287-2758

Fax: +1 (507) 287-2722

Email:

yawnX002@umn.edu

Date submitted: 15/05/03

Date Accepted: 08/09/03

Prim Care Resp J 2003; 12(3):82-85
Surveillance for asthma--United States, 1960-1995. :

Morb Mortal Wkly Rep CDC Surveill Summ

1998;47(1):1-27.

5. Sly RM. Changing prevalence of allergic rhinitis and asthma. Ann Allergy Asthma Immunol 1999;82(3):233-48. 6. Yeatts K, Shy C, Wiley J, Music S. Statewide adolescent asthma surveillance. J Asthma 2000;37(5):425-34.

7. Slezak JA, Persky VW, Kviz FJ, Ramakrishnan V, Byers C. Asthma prevalence and risk factors in selected Head Start sites in Chicago. J Asthma 1998;35(2):203-12. 8. Silverstein MD, Mair JE, Katusic SK, Wollan PC, O'Connell EJ, Yunginger JW. School attendance and school performance: A population-based study of children with asthma. J of Ped 2001;139(2):278-283.

9. Maier WC, Arrighi HM, Morray B, Llewllyn C, Redding GJ. The impact of asthma and asthma-like illness in Seattle school children. J Clin Epidem 1998;51(7):55768.

10. Joseph CL, Foxman B, Leickly FE, Peterson E, Ownby D. Prevalence of possible undiagnosed asthma and associated morbidity among urban schoolchildren. $J$ of Ped 1996;129(5):735-42.

11. Czyszczon A, Arduino K, Asmussen L, Grant E, Weiss K, Lewis D. Investigation of discordant reporting of quality of life assessments between children with asthma and their caregivers. [abstract] Abstra Book Assoc Health Serv Res 1999;16:17

12. Reichenberg K, Broberg AG. The Paediatric Asthma Caregiver's Quality of Life Questionnaire in Swedish parents. Acta Paediatr 2001:90(1):45-50.

13. Blaiss MS. Measuring outcomes in pediatric asthma. Allergy Asthma Proc 2001; 22: 63-5.

14. Townsend M, Feeny DH, Guyatt GH, Furlong WJ, Seip AE, Dolovich J. Evaluation of the burden of illness for pediatric asthmatic patients and their parents. Ann Allergy 1991;67(4):403-8.

15. Osman LM, Baxter-Jones AD, Helms PJ. Parents' quality of life and respiratory symptoms in young children with mild wheeze. EASE Study Group. Eur Respir J 2001;17(2):254-8.

16. Osman L, Silverman M. Measuring quality of life for young children with asthma and their families. Eur Respir J 1996;21(Suppl):34s-41s.

17. Williams S, Sehgal M, Falter K, Dennis R, Jones D, Boudreaux J, Homa D, Raskin-Hood C, Brown C, Griffith M, Redd S. Effect of asthma on the quality of life among children and their caregivers in the Atlanta Empowerment Zone. J Urban Health 2000;77(2):268-79. 18. Gartland HY, Day HD. Family predictors of the incidence of children's asthma symptoms: expressed emotion, medication, parent contact, and life events. $J$ Clin Psychol 1999;55(5):573-84.

19. Sawyer MG, Spurrier N, Kennedy D, Martin J. The relationship between the quality of life of children with asthma and family functioning. $J$ Asthma 2001;38(3):27984.

20. Juniper EF, Guyatt GH, Feeny DH, Ferrie PJ, Griffith LE, Townsend M. Measuring quality of life in the parents of children with asthma. Qual Life Res 1996;5(1):27-34. 21. Crabtree BF, Miller WL, eds. Doing qualitative research in primary care: Multiple strategies (2nd edition). Newbury Park, CA: Sage Publications; 1999.

22. NIH Publication. Guidelines for the Diagnosis and Management of Asthma. Expert Panel Report 2. US Department of Health and Human Services. July. 1997 No. 97-4051. 